\title{
HUBUNGAN INDEKS MASSA TUBUH DENGAN STATUS KONTROL PASIEN ASMA DI RSUD KOTA MATARAM TAHUN 2019
}

\author{
Tri Wira Jati Kusuma Hamdin*, Risky Irawan ${ }^{* *}$, Dian Rahadianti***, \\ Kadek Dwi Pramana***** \\ Fakultas Kedokteran Universitas Islam Al-Azhar \\ Jl. Unizar No. 20 Turida Mataram \\ Email: Triwirajatikusuma@gmail.com
}

\begin{abstract}
ABSTRAK
Latar Belakang: Asma merupakan salah satu masalah utama baik di negara maju dan negera berkembang. Pada tahun 2017 angka kejadian asma di berbagai negara sekitar 1-18\% dan diperkirakan sebanyak 300 juta penduduk di dunia menderita asma menurut Global Initiatif for Astma (GINA). Kejadian asma dipengaruhi oleh banyak faktor diantaranya usia, jenis kelamin, perokok aktif maupun pasif, genetik, Indeks massa tubuh (IMT. Penurunan faal paru dapat diakibatkan IMT berlebih kurang sehingga meningkatkan terjadinya asma. Indeks Massa Tubuh (IMT) merupakan salah satu faktor pejamu penyebab asma yang dapat di modifikasi karena reversibel. Seseorang dengan IMT berlebih (over-weight-obesitas) maupun IMT kurang (underweight) cenderung memiliki perubahan pada sistem tubuh yang menimbulkan perburukan pada asma sehingga menjadi tidak terkontrol. Tujuan: Mengetahui hubungan indek massa tubuh dengan status kontrol pasien asma di RSUD Kota Mataram Tahun 2019. IMT bersifat Metode: Penelitian ini merupakan analitik observasional, dengan rancangan cross sectional. Sumber data yang digunakan dalam penelitian ini berupa data sekunder dari rekam medik pasien asma yang menjalani rawat jalan di RSUD Kota Mataram 2019. Sampel pada penelitian ini berjumlah 118 orang. Analisis data menggunakan rank spearman. Hasil: Hasil analisis menggunakan Rank Spearmen didapatkan nilai p-value 0,000 ( $\mathrm{p}$-value 0,05), yang berarti terdapat hubungan antara IMT dengan status kontrol pasien asma di RSUD Kota Mataram tahun 2019. Kesimpulan: Terdapat hubungan antara Indeks Massa Tubuh dengan status kontrol pasien asma di RSUD Kota Mataram tahun 2019.
\end{abstract}

Kata Kunci: Indeks Massa Tubuh, Status Kontrol, Asma.

\section{ABSTRACT}

Background: Asthma is one of the main problems in both developed and developing countries. In 2017 the prevalence of asthma incidence in various countries was around 1 - 
$18 \%$ and an estimated 300 million people in the world suffer from asthma according to the Global Initiatiffor Astma (GINA). The asthma incidence influenced by many factors. These factors include age, sex, active and passive smoker, genetics, body mass index (BMI). Decreased lung function can be caused by excess BMI and low BMI which increases the asthma insidence. Body Mass Index (BMI) is one of the factors of host that caused asthma can be modified because they were reversible. A person with an over-weight-obesity and underweight BMI tends was have changes in the body's systems that worsen asthma so that becomes uncontrollable. Purpose: Knowing the correlation between body mass index and control status of asthma patients at RSUD Kota Mataram in 2019. Methods: This reseacrh was an observational analytic study, with a cross sectional design. The data source used in this study is secondary data from the medical records of asthma patients who was undergoing outpatient care at the Mataram City Hospital 2019. Data was collected from 118 samples. Data analysis used rank spearman. Results There is a correlation between Body Mass Index and the control status of asthma patients at Mataram City Hospital in 2019. Key Words: Asthma, body mass index, asthma control status.

Key Words: body mass index, control status, asthma.

\section{PENDAHULUAN}

Perubahan tren penyakit saat ini terjadi dari penyakit menular ke penyakit yang tidak menular. Salah satu contoh penyakit tidak menular dengan tingkat kejadian semakin tinggi adalah asma. Penyakit asma merupakan gangguan inflamasi kronik pada saluran napas yang melibatkan banyak sel dan elemennya serta menjadi masalah kesehatan masyarakat serius di seluruh dunia. Ketika tidak mendapat penanganan yang tepat, asma dapat menimbulkan kematian pada penderitanya. Asma dapat menyebabkan penurunan produktivitas, serta menurunkan kualitas hidup bagi penderitanya (Rahajeng, 2012; Oemiati et al, 2010; GINA, 2017).
Asma merupakan salah satu masalah utama baik di negara maju dan negera berkembang. Pada tahun 2017 angka kejadian asma di berbagai negara sekitar 1-18\% dan diperkirakan sebanyak 300 juta penduduk di dunia menderita asma menurut Global Initiatif for Astma (GINA). Prevalensi asma tertinggi di Indonesia adalah provinsi Daerah Istimewa Yogyakarta (DIY) sebesar 4,5\%, sementara provinsi Nusa Tenggara Barat berada diurutan 7 secara nasional dengan prevalensi 2,5\% (GINA, 2017; Riskesdas, 2018).

Angka kejadian asma yang tinggi maka status kontrol pasien asma juga memiliki variasi berbeda-beda di 
setiap provinsi. Terdapat beberapa status kontrol pasien asma yakni terkontrol, terkontrol sebagian dan tidak terkontrol. Status tersebut didasarkan pada tingkat produktivitas yang terganggu, gejala harian, gejala nokturnal, fungsi paru dan eksaserbasi. Status terkontrol memiliki gambaran gejala kurang dari dua kali dalam seminggu. Status terkontrol sebagian memiliki gambaran gejala harian lebih dari dua kali seminggu, menggunakan reliever lebih dari dua kali seminggu dan PEF $<80 \%$ (perkiraan atau kondisi terbaik bila diukur). Status tidak terkontrol memiliki gambaran gejala harian tiga kali atau lebih seminggu (Riskesdas, 2018; PDPI, 2003).

Kejadian asma dipengaruhi oleh banyak faktor diantaranya usia, jenis kelamin, perokok aktif maupun pasif, genetik, Indeks massa tubuh (IMT. Penurunan faal paru dapat diakibatkan IMT berlebih dan IMT kurang sehingga meningkatkan terjadinya asma (Otrowski et all, 2006; P2PTM Kemenkes, 2019; Kemenkes, 2019). Hubungan antara IMT dengan status kontrol pasien asma masih belum dapat dinyatakan secara jelas karena masih sedikit penelitian yang melihat hubungan dua variabel ini. Hasil penelitian mengenai hubungan antara IMT dengan status kontrol pasien asma telah dilakukan oleh peneliti sebelumnya namun masih didapatkan hasil yang berbeda. Penelitian oleh Amalia et al menyebutkan bahwa status kontrol pasien asma dengan IMT normal memilki status kontrol lebih baik dibandingkan IMT berlebih dan kurang (Amalia et al,2016; Andriani et al, 2016). Hasil penelitian ini tidak sejalan dengan penelitian yang dilakukan oleh Akbar yang menunjukkan bahwa tidak ada hubungan bermakna antara IMT dan status kontrol (Ariestha et al, 2010; Akbar, 2014; Sastre et al ,2010). Hubungan lain antara underweight dan obstruksi saluran pernapasan dapat dilihat dari efek negatif malnutrisi terhadap struktur pernapasan. Malnutrisi mempunyai pengaruh negatif terhadap struktur, elastisitas, dan fungsi paru, kekuatan dan ketahanan otot pernapasan, mekanisme pertahanan imunitas paru, dan pengaturan napas yang nantinya meningkatkan gangguan pernapasan termasuk asma (Fasitasari, 2013; Fujianti et al, 2015).

Perubahan tren penyakit dunia meyebabkan asma menjadi salah satu masalah kesehatan dunia dengan angka kejadian yang terus meningkat yang diikuti dengan keragaman status kontrol pasien asma. Indeks Massa Tubuh (IMT) merupakan salah satu faktor pejamu penyebab asma yang dapat di modifikasi karena bersifat reversibel. Seseorang dengan IMT berlebih (over-weightobesitas) maupun IMT kurang (underweight) cenderung memiliki 
perubahan pada sistem tubuh yang menimbulkan perburukan pada asma sehingga menjadi tidak terkontrol. Oleh karena itu untuk melengkapi penelitian sebelumnya peneliti tertarik untuk

\section{METODE PENELITIAN}

\begin{tabular}{lcr}
\multicolumn{1}{c}{ Jenis } & penelitian ini adalah \\
penelitian & kuantitatif & analitik \\
observasional & dengan & rancangan
\end{tabular}
penelitian yang digunakan adalah cross sectional study. Penelitian ini dilaksanakan di Rumah Sakit Umum Daerah Kota Mataram. Waktu dan pengumpulan data penelitian dimulai pada 15 September - 15 Oktober tahun 2020. Populasi pada penelitian adalah seluruh pasien asma yang menjalani rawat jalan di Rumah Sakit Umum Daerah Kota Mataram periode Oktober 2019- Desember 2019. penelitian ini menggunakan teknik nonprobability sampling dengan cara pengambilan menggunakan purposive sampling. Jumlah sampel minimal yang harus didapatkan peneliti adalah 115 sampel.

Kreteria inklusi dalam penelitian ini yaitu

(1) Semua pasien asma stabil yang menjalani rawat jalan di Poli Paru RSUD Kota Mataram periode Oktober sampai dengan Desember 2019. (2) Usia 18-60 tahun. Kriteria eksklusi pada penelitian ini adalah (1) Pasien dengan data rekam medik tidak lengkap (Berat badan, tinggi badan, dan nilai VEP1/KVP) (2) Pasien meneliti hubungan antara IMT dengan status kontrol pada pasien asma di Rumah Sakit Umum Daerah Kota Mataram tahun 2019.

asma stabil dengan penyakit metabolik (DM, hipertiroid). (3) Pasien memiliki penyakit paru lain selain asma (PPOK, TB paru, bronkiektasis, emfisema dan lain lain) (4) Pasien asma dengan penyakit immunocompromised (HIV) (5) Pasien asma dengan keganasan (tumor paru dan ekstra paru). Pada penelitian ini, analisis data dilakukan menggunakan komputer melalui program Statistical Package For The Social Sciences (SPSS) for Windows versi 25. Dalam analisis ini uji statistik yang digunakan adalah rank Spearmen.

\section{HASIL}

Tempat pengambilan data dilakukan di Rumah Sakit Umum Daerah Kota Mataram. Populasi penelitian yang digunakan adalah seluruh pasien asma yang menjalani rawat jalan di RSUD Kota Mataram tahun 2020. Pengambilan Sampel digunakan teknik nonprobability samplingdengan cara purposive sampling.

Tabel 1. Karakteristik Pasien Berdasarkan Usia

\begin{tabular}{ll}
\hline Usia & Frekuensi \\
\hline
\end{tabular}




\begin{tabular}{lll}
\hline & $\begin{array}{l}\text { Jumlah } \\
(\mathbf{n})\end{array}$ & $\begin{array}{l}\text { Persentase } \\
(\boldsymbol{\%})\end{array}$ \\
\hline $20-28$ & 35 & 37.2 \\
tahun & & \\
$29-39$ & 38 & 28.0 \\
tahun & & \\
$40-50$ & 17 & 11.9 \\
tahun & & \\
$>51$ & 28 & 22.9 \\
\hline Total & 118 & 100.0 \\
\hline
\end{tabular}

Berdasarkan data yang diperoleh, dari 118 responden didapatkan rata-rata pada usia 37 tahun dengan usia terendah adalah 20 tahun dan usia tertinggi 60 tahun. Usia yang paling banyak adalah antara 29-39 tahun. Hasil tersebut dijelaskan pada tabel tabel 1.

Tabel 2. Karakteristik Pasien

Berdasarkan Jenis Kelamin.

\begin{tabular}{cll}
\hline Jenis & \multicolumn{2}{c}{ Frekuensi } \\
\cline { 2 - 3 } Kelamin & Jumlah & Persentase \\
& $(\mathbf{n})$ & $(\boldsymbol{\%})$ \\
\hline Laki-laki & 81 & 68.6 \\
Perempuan & 37 & 31.4 \\
\hline Total & 118 & 100.0 \\
\hline
\end{tabular}

Berdasarkan data yang diperoleh, dari 118 responden didapatkan bahwa jenis kelamin laki-laki terbanyak yaitu 81 responden (68,6\%), sedangkan yang berjenis kelamin perempuan sebanyak 37 responden $(31,4 \%)$. Hasil tersebut dilihat pada tabel 2.
Tabel 3. Karakteristik Pasien Berdasarkan Berat Badan.

\begin{tabular}{ccc}
\hline Berat & \multicolumn{2}{c}{ Frekuensi } \\
\cline { 2 - 3 } Badan & Jumlah & Persentase \\
& $(\mathbf{n})$ & $(\%)$ \\
\hline $38-46 \mathrm{Kg}$ & 8 & 6.8 \\
$47-55 \mathrm{Kg}$ & 30 & 25.4 \\
$56-64 \mathrm{Kg}$ & 37 & 31.4 \\
$65-73 \mathrm{Kg}$ & 26 & 22.0 \\
$>74 \mathrm{Kg}$ & 17 & 14,4 \\
\hline Total & 118 & 100.0 \\
\hline \multicolumn{3}{c}{ data } \\
\multicolumn{3}{c}{ Berdasarkan }
\end{tabular}

diperoleh, dari 118 responden didapatkan rata-rata berat badan adalah $61 \mathrm{~kg}$ dengan berat badan terendah $38 \mathrm{~kg}$ dan berat badan tertinggi $80 \mathrm{~kg}$. Berat badan terbanyak adalah 56-64 Kg. Hasil tersebut dilihat pada Tabel 3 .

\section{Tabel 4. Karakteristik Pasien}

\section{Berdasarkan Tinggi Badan.}

\begin{tabular}{ccc}
\hline \multirow{2}{*}{ Tinggi } & \multicolumn{2}{c}{ Frekuensi } \\
\cline { 2 - 3 } Badan & $\begin{array}{c}\text { Jumlah } \\
(\mathbf{n})\end{array}$ & $\begin{array}{c}\text { Persentase } \\
(\%)\end{array}$ \\
\hline $\begin{array}{c}150-154 \\
\mathrm{~cm}\end{array}$ & 18 & 15,3 \\
$155-159$ & 29 & 24.6 \\
$\mathrm{~cm}$ & & \\
$160-164$ & 38 & 32.2 \\
$\mathrm{~cm}$ & & \\
$165-169$ & 27 & 22.9 \\
$\mathrm{~cm}$ & & \\
$>169 \mathrm{~cm}$ & 6 & 5.1 \\
\hline Total & 118 & 100,0 \\
\hline
\end{tabular}


Berdasarkan data yang diperoleh, dari 118 responden didapatkan rata-rata tinggi adalah $160 \mathrm{~cm}$ dengan tinggi badan terendah $150 \mathrm{~cm}$ dan tinggi badan tertinggi $170 \mathrm{~cm}$. Kelompok tinggi badan terbanyak adalah 160-164 cm. Hasil tersebut dilihat pada tabel 4.

Tabel 5. Karakteristik Pasien Berdasarkan IMT.

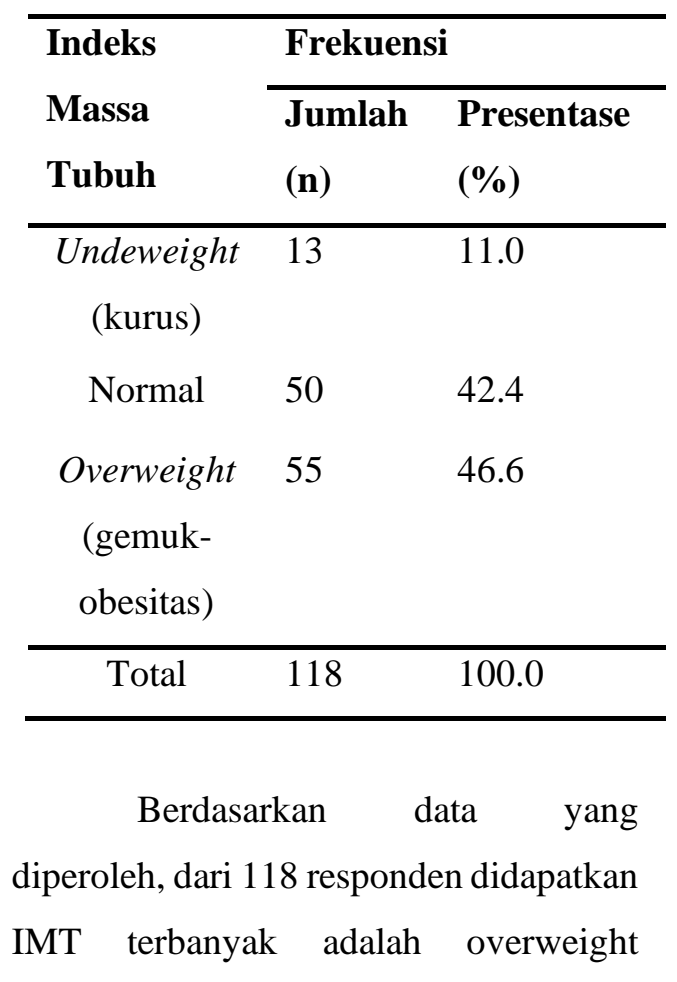

$(46,6 \%)$ sedangkan IMT paling sedikit yakni underweight (11,0\%). Hasil tersebut dilihat pada Tabel 5.

Tabel 6. Karakteristik Pasien Status Kontrol Asma

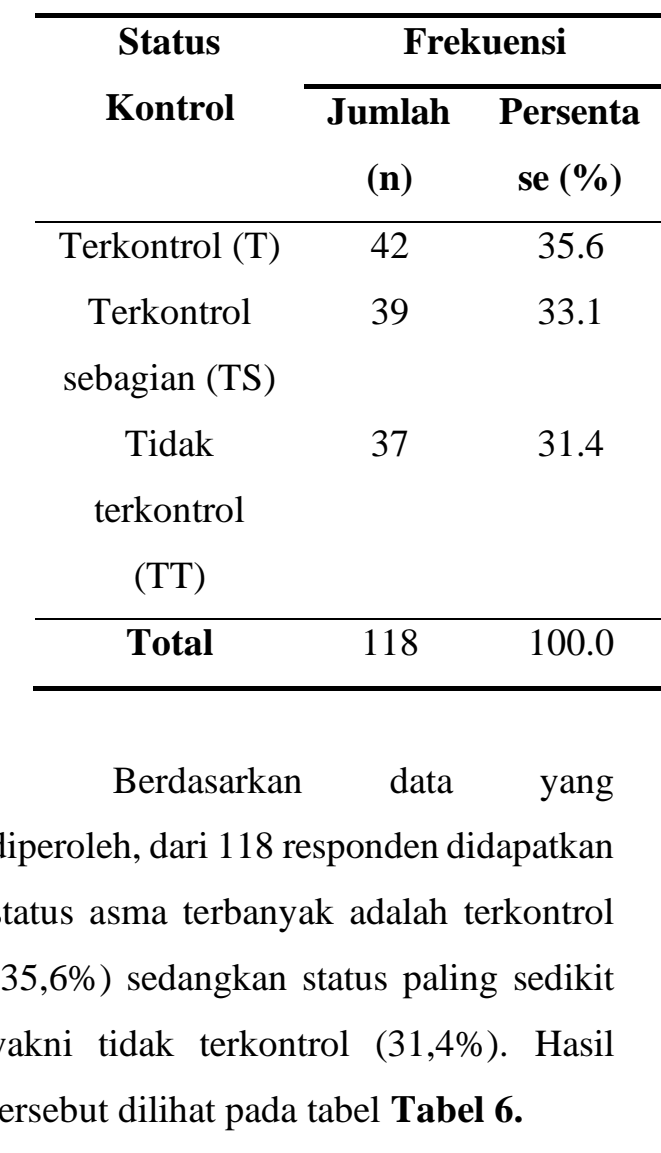

Tabel 7. Hubungan IMT dengan status kontrol asma.

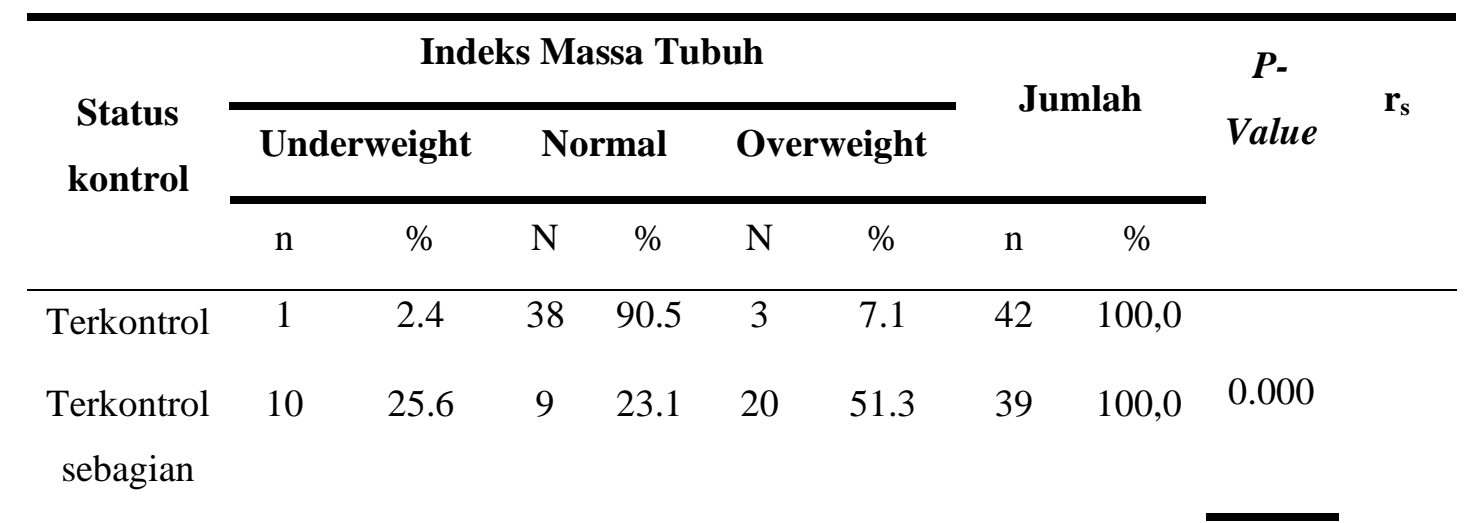




\begin{tabular}{cccccccccc}
$\begin{array}{c}\text { tidak } \\
\text { terkontrol }\end{array}$ & 2 & 5.4 & 3 & 8.1 & 32 & 86.5 & 37 & 100,0 & 0.51 \\
& & & & & & & & \\
\cline { 1 - 6 } Total & 13 & 11,0 & 50 & 42.4 & 55 & 46,6 & 118 & 100,0 & \\
\hline
\end{tabular}

\begin{abstract}
Berdasarkan analisis bivariat yang dilakukan dari 118 responden didapatkan hasil yang memiliki status terkontrol paling banyak pada kelompok
\end{abstract} IMT normal $(90,5 \%)$ dan paling sedikit pada kelompok IMT underweight $(2,4 \%)$. Responden yang memiliki status terkontrol sebagian paling banyak pada IMT dalam kategori overweight $(51,3 \%)$ dan paling sedikit dengan IMT normal $(23,1 \%)$. Responden yang memiliki status tidak terkontrol memiliki IMT dalam kategori overweight (gemukobesitas) terbanyak $(86,5 \%)$ dan paling sedikit pada IMT underweight $(5,4 \%)$.

\section{PEMBAHASAN}

Penelitian ini bertujuan untuk mengidentifikasi hubungan IMT dengan status kontrol pasien asma di RSUD Kota Mataram. Jenis penelitian ini adalahanalitik observasional dengan rancangan penelitian yang digunakan cross sectional. Total sampel yang didapatkan dalam penelitian ini menggunakan sampel 118 pasien.

Berdasarkan karekteristik jenis kelamin didapatkan laki-laki dengan

jumlah terbanyak. Hal tersebut serupa dengan penelitian yang di lakukan
Hasil analisis yang menggunakan Spearman rank didapatkan nilai $p$-value 0,000 ( $\mathrm{P}$-value $\leq 0,05)$ yang artinya Ho ditolak, hasil tersebut menunjukkan bahwa terdapat hubungan yang signifikan antara IMT dengan status kontrol pasien asma di RSUD Kota Mataram tahun 2020. Nilai koefisien korelasi Rank Spearman yang didapatkan pada penelitian ini adalah sebesar 0.512 yang berarti antara kedua variabel memiliki hubungan sedang. Berdasarkan arah hubungan, hasil analisis menunjukkan arah hubungan kedua variabel adalah positif.

Runtuwene et al (2016) dengan sampel penenelitian 41 laki-laki dan 33 perempuan. Penderita asma didominasi oleh laki-laki diakibatkan diameter saluran pernapasan pada laki-laki lebih sempit dari pada perempuan sehingga obstruksi akan lebih mudah terjadi (Runtuwene et al, 2016).

Karakteristik usia responden dari 118 responden, didapatkan prevalensi tertinggi adalah usia 29-39 tahun. Hasil penelitian ini sesuai dengan penelitian yang dilakukan oleh Amalia et al (2016) yang menunjukan bahwa mayoritas usia pasien asma adalah 25-35 tahun. Penelitian yang di lakukan Andayani et al 
(2014) melaporkan hal yang sama yakni usia asma terbanyak adalah usia dewasa. Menurut Andriani et al (2016) menjelaskan bahwa asma dapat terjadi pada semua kelompok usia mulai dari anak hingga dewasa. Seiring bertambahnya usia sering terjadi underdiagnosed yang diakibatkan penurunan sensitivitas terhadap gejala, gejala klinis yang tidak spesifik dan sering menjadi faktor perancu dari komorbid (Amalia et al, 2016; Andayani et al, 2014; Andriani et al,2016)

Hasil analisis univariat berdasarkan IMT yang didapatkan dari 118 responden paling sedikit pasien masuk dalam kategori IMT underweight $(11,0 \%)$ dan masuk dalam kategori IMT overweight $(46,6 \%)$ terbanyak. Hal ini sesuai dengan teori terdahulu Andriani et al (2016) bahwa pasien asma banyak memiliki IMT overweight diakibatkan ketakutan untuk beraktivitas yang justru memicu terjadinya asma sehingga mengarah ke gaya hidup yang santai dan peningkatan resiko obesitas (Andriani et al, 2016)

Hasil analisis univariat berdasarkan status kontrol asma dari 118 pasien didapatkan status terkontrol terbanyak $(35,6 \%)$. Hasil paling sedikit didapatkan pada status tidak terkontrol $(31,4 \%)$. Hal tersebut menunjukkan pasien asma di RSUD Kota Mataram memiliki terapi dengan keberhasilan cukup baik.
Berdasarkan analisis bivariat menunjukan bahwa terdapat hubungan yang bermakna IMT dengan status kontrol pasien asma di RSUD Kota Mataram. Penelitian ini didukung oleh penelitian yang dilakukan oleh Andriani et al (2016) dan Amalia et al (2016) yang menunjukan terdapat hubungan yang signifikan antara IMT dengan status kontrol pasien asma. Dari hasil analisis Spearman 0,000 artinya kekuatan korelasi antara kedua variabel memiliki korelasi sedang, hal ini menyatakan bahwa sebagian besar pasien asma di RSUD Kota Mataram memiliki status gizi yang baik. Berdasarkan arah hubungan, hasil analisis menunjukkan arah hubungan kedua variabel adalah positif yang berarti bahwa kenaikan 1 variabel berasosiasi dengan peningkatan variabel lain (searah). Hal tersebut menunjukkan bahwa semakin terganggunya IMT pasien asma, maka status kontrol pasien asma akan semakin buruk.

Sesuai dengan teori sebelumnya pada obesitas terdapat dua mekanisme dasar yang menjelaskan bagaimana hubungannya dengan status kontrol pasien asma termasuk pengaruhnya pada fungsi fisiologi paru. Mekanisme tersebut yaitu perubahan mekanik dan kimiawi. Perubahan mekanik yang terjadi pada obesitas yakni peningkatan jaringan adiposa di dinding dada dan 
dinding perut. Peningkatan kerja sistem pernapasan akibat peurunan volume residu, kapasitas vital dan kapasitas total paru akibat peningkatan jaringan adiposa pada seseorang dengan IMT berlebih. Sitokin, leptin, TNF a dan interleukin 6 di sekresi berlebih oleh jaringan adiposa sehingga menimbulkan efek proinflamasi pada saluran napas yang menyebabkan hiperesponsif sehingga menimbulkan obstruksi saluran napas. Kekambuhan asma karena IMT yang terganggu akan menyebabkan eksasebasi asma semakin sering terjadi. Eksaserbasi yang terjadi mengakibatkan pasien asma semakin sering mendapatkan terapi yang memperburuk status kontrol asma pasien tersebut (Parameswaran et al 2000; Sutherland et al. 2008).

Data yang didapatkan pada kelompok underweight memiliki status tidak terkontrol diakibatkan perubahan mekanik dan proses inflamasi pada saluran napas. Seseorang dengan IMT underweight timbul efek negatif malnutrisi terhadap sistem pernapasan. Terjadi perubahan struktur pada tulang rusuk yang menjadikan dinding dada lebih kaku sehingga daya compliance paru menurun. Kaku pada dinding dada menyebabkan usaha yang diperlukan untuk bernapas lebih berat (Fasitasari, 2013). IMT kelompok underweight terjadi sedikit penuunan limfosit $\mathrm{T}$ yang berperan dalam proses atopi pada asma
(Yudhawati, et al. 2017). Perubahan yang terjadi menyebabkan seseorang dengan penyakit asma akan lebih sering terjadinya kekambuhan. Asma dengan tingkat kekambuhan yang tinggi akan memperburuk status kontrol pasien asma Dengan diketahuinya korelasi antara indeks massa tubuh (IMT) dengan status kontrol pasien asma, diharapkan agar asupan makanan pasien lebih diperhatikan dengan cara mendeteksi dan menangani secara dini gizi pada pasien. Salah satu cara awal untuk mendeteksi status gizi pasien yaitu dengan indikator indeks massa tubuh. Deteksi dini status gizi diharapkan dapat menurunkan angka morbiditas dan mortalitas pasien dan meningkatkan kualitas hidup pasien asma.

\section{KESIMPULAN}

Terdapat hubungan yang signifikan antara Indeks Massa Tubuh dengan status kontrol pasien asma di RSUD Kota Mataram tahun 2020 ditandai dengan nilai $p$-value 0,000 ( $p$ value $<0,050$ ) dan nilai koefisien 0,152 menandakan kekutan hubungan sedang. Serta hasil analisis menunjukkan arah hubungan kedua variabel adalah positif.

Pada penelitian ini menggunakan data sekunder yang dapat menimbulkan perbedaan kondisi pasien. Pengukuran data pada penelitian ini tidak dilakukan secara langsung dan pengukuran 
berulang. Diharapkan pada penelitian berikutnya dapat menambahkan data primer. Serta perlu penelitian lebih lanjut untuk mengetahui pengaruh IMT terhadap status kontrol astma dengan disain penelitian case control atau cohort prospektif.

\section{DAFTAR PUSTAKA}

Akbar, F. 2014. Hubungan Indeks Massa Tubuh Dengan Tingkat Kontrol Asma Pada Pasien Asma di RSU Dokter Soedarso Pontianak. Skripsi. Fakultas Kedokteran Universitas Tanjung Pura.

Amalia, V. et al. 2016. Hubungan Obesitas Dengan Kontrol Asma Pada Usia 20-35 Tahun. Fakultas Kedokteran Universitas Trisakti.

Andayani, N. et al. 2014. Hubungan Tingkat Pengetahuan Pasien Asma Dengan Tingkat Kontrol Asma Di Poliklinik Paru RSUD Dr. Zanoel Abidin Banda Aceh. Fakultas Kedokteran Syiah Kuala Banda Aceh.

Andriani, F. et al. 2016. Gambaran Karakteristik Tingkat Kontrol Penderita Asma Berdasarkan Indeks Massa Tubuh (IMT) di Poli Paru RSUP. Dr. M. Djamil Padang pada Tahun 2016.

Ariestha, R. et al. 2010. Hubungan Tingkat Kontrol Asma Dengan Nilai VEP1/VEP1(\%) Prediksi dan Rasio VEP1/KVP (\%) Prediksi pada Pasien Asma Bronkial di RSUD Dokter Soedarso Pontianak. Skripsi. Fakultas Kedokteran Universitas Tanjung Pura.

Bateman, E. et a. 2011. Global strategy For Asthma Management and Prevention, Global Initiative For Asthma, Cape Town South Africa.

Berawi, K et al. 2017. Faktor Risiko Obesitas dan Kejadian Asma. Jurnal Majority. 6(2): 6-11.
Dahlan, M. 2011. Statistik Untuk Kedokteran dan Kesehatan. Jakarta: Salemba Medika.

Dahlan, S. 2014. Statistik Untuk Kedokteran dan KesehatanEdisi 6. Jakarta. Salemba Medika.

Departemen Kesehatan RI. 2009. Pedoman Pengendalian Penyakit Asma.

Depkes. 2003. Pedoman Praktis Terapi Gizi Medis. Di unduh dari http://www.depkes.go.id/ 20 Juli 2020.

Djojodibroto, D. Respirologi (Respiratory Medicine). EGC: Jakarta.2009.

Fasitasari, M. 2013. Terapi Gizi pada Lanjut Usia dengan Penyakit Paru Obstruktif Kronik (PPOK). Sains Medika. 5(1):50-61.

GINA (Global Initiative for Astma). 2017. Pocket Guide For Asthma Management and Prevention.

GINA (Global Initiative for Astma). 2019. Pocket Guide for Asthma Management and Prevention. Cape Town: Global Initiative for Asthma.

Kemenkes. 2008. Keputusan Kementrian Kesehatan Republik Indonesia Tentang Pedoman Pengendalian Penyakit Asma. Di unduh dari http://www.kemenkes.go.id/ 20 Juli 2020.

Kemenkes RI .2019. Pedoman Praktis Memantau Status Gizi Orang Dewasa (pp.1-7).

KEPPKN. 2017. Pedoman dan Standar Etik Penelitian dan Pengembangan Kesehatan Nasional. Kementerian Kesehatan Republik Indonesia.

Notoatmodjo, S. 2014. Metodologi Penelitian Kesehatan. Edisi Revisi Cetakan Kedua. Jakarta: PT. Rineka Cipta.

Oemiati, R. et al .2010. Faktor-Faktor Yang Berhubungan Dengan Penyakit Asma di Indonesia. XX (41-50).

Openi. 2012. Patofisiologi asthma. Diunduh dari http://www.openi.nlm.nih.gov 22 juni 2020. 
Ostrowski, S et al. 2006. Factors Influencing Lung Function: Are The Predicted. Journal of physiology and pharmacology, 57.

P2PTM (Direktorat Pencegahan dan Pengendalian Penyakit Tidak Menular) Kemenkes RI. 2019. Cara Mengukur Indeks Massa Tubuh. Di unduh dari http://p2ptm.kemkes.go.id/infogra phicp2ptm/obesitas/tabel-batasambang-indeks-massa-tubuh-imt 19 Juni 2020.

Parameswaran, N. et al. 2000. Addition of Intravenous Aminophyline to Beta2-Agonis In Adults With Acute Asthma. Cochrane Database Syst Rev; 4: CD002742

Persatuan Dokter Paru Indonesia (PDPI). 2003. Pedoman Diagnosis \& Penatalaksanaan Asma Di Indonesia. Diunduh dari www.klikpdpi.com/konsensus/as ma/asma.pdf 22 juni 2020.

Persatuan Dokter Paru Indonesia (PDPI). 2018. Pedoman Diagnosis \& Penatalaksanaan Asma Di Indonesia. Diunduh dari www.klikpdpi.com/konsensus/as ma/asma.pdf 25 juni 2020.

Universitas Sam Ratulangi Manado.

Sastre, J. et al. 2010. Increased body mass index does not lead to a worsening of asthma control in a large adult asthmatic population in Spain, J Inverstig Allergol Clin Immunol 20 (7):551-557.

Sastroasmoro, S. 2014. Dasar dasar Metodologi Penelitian Klinis. Jakarta: Sagung Seto.

Sudoyo, A. et al. 2014. Buku Ajar Ilmu Penyakit Dalam Jilid I Edisi VI. Jakarta; Intena Publishing.

Sugiyono. 2017. Metode Penelitian Kuantitatif, Kualitatif, dan $R \& D$. Bandung: Alfabeta, CV.

Sundaru, H. 2006. Asma Bronkial. Jakarta: Departemen Ilmu Penyakit Dalam FK UI.

Sutherland, T. et al. 2008. The association between obesity and asthma: interactions between
Persatuan Dokter Paru Indonesia (PDPI). 2019. Pedoman Diagnosis \& Penatalaksanaan Asma Di Indonesia. Diunduh dari www.klikpdpi.com/konsensus/as ma/asma.pdf 25 juni 2020.

Rahajeng, E. et al. 2012. Prevalensi hipertensi dan determinannya di Indonesia. Maj Kedokteran Indonesi.;59(12):580-7.

Rai, Ida Bagus Ngurah et al. 2016. Asthma Meeting: Comprehenssive Approach of Asthma.Jakarta Timur: Sarana Bangun Pustaka.

Riskesdas (2018). Badan Penelitian dan Pengembangan Kesehatan Kementerian RI tahun 2018. di unduh dari http://www.depkes.go.id/resources /download/infoterkini/materi_rako rpop 2018/Hasil\%20Riskesdas\%2 02018.pdf 26 Februari 2020.

Riyanto, A. 2017. Aplikasi Metodologi Penelitian Kesehatan. Yogyakarta: Nuha Medika.

Runtuwene, K et al. 2016. Prevalensi dan faktor-faktor risiko yang menyebabkan asma pada anak di RSU GMIM Bethesda Tomohon periode Agustus 2011 - Juli 2016. Skripsi. Fakultas Kedokteran systemic and airway inflammation. American journal of respiratory and critical care medicine, 178 (5), 469-475.

Wilson, N. 2015. Gastroeosophageal reflux and childhood asthma. The acid test. Thorax, 97.

Yudhawati, R. et al. 2017. Imunopatogenesis Asma. Departemen Pulmonologi dan Ilmu Kedokteran Respirasi, Fakultas Kedokteran Universitas Airlangga/RSUD Dr. Soetomo. Jurnal Respirasi (JR). 3(1) :26-33. 